\section{Comparison of Bovine Bone Sialoprotein and Serum Orosomucoid}

IN recent investigations ${ }^{1}$ a sialoprotein was isolated from bovine cortical bone and some similarities with the orosomucoid ( $\alpha_{1}$-acid glycoprotein $)^{2}$ of bovine plasma were noted. It was considered to be of some interest, therefore, to compare these two substances under similar conditions of isolation and analysis.

A modified procedure was used for isolating the sialoprotein from bone extracts, using chromatogruphy on 'Amberlite CG-50' resin followed by the separation of the insoluble cetylpyridinium salt. This method has been described in detail elsewhere ${ }^{3}$. Orosomucoid was prepared from Cohn's bovine plasma Fraction VI (L. Light and Co., Ltd.) using ion-exchange chromatography. When a solution of Fraction VI in 0.1 M acetate buffer $(p H$ 5.0) was applied to a column of 'Amberlite $C G-50$ ' resin equilibrated with the same buffer, the effluent contained mainly $\alpha_{1}$-glycoproteins, but no material forming a precipitate with cetylpyridinium chloride could be detected. The orosomucoid was separated from the other proteins in this fraction by further ehromatography on carboxymethyl cellulose at $p \mathrm{H} 4.1$ as described by Bezkorovainy and Winzler ${ }^{4}$, and Bezkorovainy and Doherty ${ }^{5}$. The final precipitation of both the sialoprotein and the orosomucoid was made with ethanol (5 vol.) containing zinc acetate $(500 \mathrm{mg} / \mathrm{l}$.) and acetic acid (to $p \mathrm{H} 5 \cdot 0)$. The precipitates were washed with ethanol and ether and dried to constant weight in vacuo over phosphorus pentoxide at room temperature.

Ultracentrifugal analysis (performed by Dr. A. R. Peacocke) showed that both preparations behaved as single components. The molecular weight of the sialoprotein was about 30,000 , which is considerably less than that of bovine orosomucoid $(49,000)$ as determined by Bezkorovainy and Doherty ${ }^{5}$. Both glycoproteins also moved as single components when examined by moving boundary and paper electrophoresis in $0.1 \mathrm{M}$ acetate buffer $(p \mathrm{H} 5 \cdot 0), 0 \cdot 1 \mathrm{M}$ diethylbarbiturate buffer $(p \mathrm{H} 7 \cdot 0)$ and $0.12 \mathrm{M}$ diethylbarbiturate buffer $(p \mathrm{H} \mathrm{8.6)}$. In all cases the sialoprotein had the greater mobility which at $p H \quad 5.0$ was 1.9 relative to orosomucoid. The staining reactions of the two fractions after paper electrophoresis were in sharp contrast. Toluidine blue, for example, stained the sialoprotein clearly but was without effect on orosomucoid; light green, on the other hand, stained orosomucoid strongly but its reaction with the sialoprotein was barely detectable. Both, however, stained readily with the periodic acid-Schiff technique.

The analytical composition (Table 1) of the two glycoproteins is in agreement with the apparent difference of acidic properties, particularly with regard to their contents of sialic acid (as $N$-acetyl neuraminic acid ${ }^{6}$ ). There were also small differences in the amounts of hexose ${ }^{7}$ (as galactose, corrected for fucose), methyl pentose (as fucose ${ }^{8}$ ) and phosphate ${ }^{9}$. The most pronounced difference, however, was found in the relative amounts of the two aminosugars separated and determined by the method of (tardel1 ${ }^{10}$ after acid hydrolysis $(2 \mathrm{~N}$ hydrochloric acid, $4 \mathrm{~h}, 100^{\circ}$ ).

The sialic acid content of the orosomucoid was considerably lower than that reported by Bezkorovainy and Doherty ${ }^{5}$ using the Ehrlich and orcinol reactions, but in some cases these methods appear to give higher values than the Warren (thiobarbituric acid) ${ }^{6}$ technique ${ }^{11}$. There

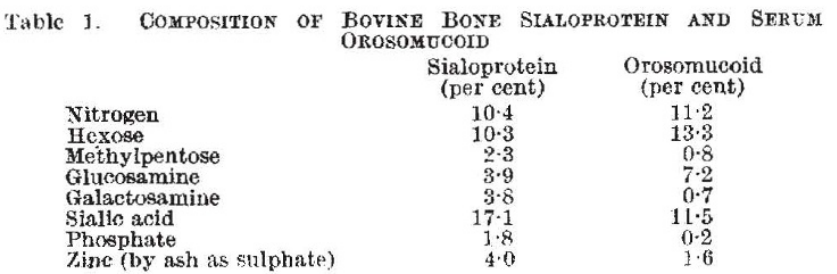

did not appear to have been any loss of sialie acid from our preparation when the electrophoretic mobility relativo to albumen was observed.

The foregoing results show several characteristies which clearly differentiate the sialoprotein from orosomucoid. Recently, another glycoprotein resembling the sialoprotein in its high sialic acid content has been isolated from human serum $^{12}$, though this had the lower mobility of an $\alpha_{2}$-glycoprotein. A preliminary investigation using wholo fresh bovino plasma, however, has not revealed any component which, either before or after fractionation, could be procipitated with cetylpyridinium chloride, or which had tho cloctrophoretic mobility and staining characteristics of the sialoprotein. These results indicate that the sialoprotein is probably formed in bone rather than being derived from the plasma proteins.

\section{Medical Rusearch Council Bone-secking T. M. Hetopes} Research Unit, The Churchill Hospital, Oxford.

'Herring, G. M., and Kent, P. W., Biochem. J., 81, 5. P (1961).

Weimer, H. E., and Winzler, R. J., Proc. Soc, Exp. Biol. Med., 90, 458 (1955). ${ }^{3}$ Herring, (7. M. First European Bone and Tooth Symposium, 1063 (Perg-
amon Press, London) (in the press).

4 Bezkorovainy, A., and Winzler, R. J., Biochim. Biophys. Acta, 49, 559 (1961).

${ }^{5}$ Bezkorovainy, A., and Doherty, D. G., Nature, 195, 1008 (1962).

'Warren, L., J. Biol. Chem., 234, 1971 (1959).

'Yemm. E. W., and Willis, A. J., Biochem. J., 57, 508 (1954).

"Dische, Z., and Shettles, L. B., J. Biol. Chem., 175, 595 (1948).

- Chen, P. S., Toribara, T. Y., and Warner, H., Analytical Chemistry, 28, 1756 (1956).

${ }^{10}$ Gardell, S., Acta Chem. Scand., 7, 207 (1953).

${ }^{13}$ Bezkorovainy, A., and Doherty, D. G., Arch. Biochem. Biophys., 96, 491 (1962).

${ }^{15}$ Schultze, H. E., Heide, K., and Haupt, H., Clin. Chim. Acta, 7, 854 (1962).

\section{Effect of Ethanol and Acetaldehyde on Liver and Brain Monoamine Oxidase}

Maynard and Sohenker ${ }^{1}$ have reported that monoamine oxidase from mouse liver is inhibited by ethanol in vitro; however, these authors could not obtain similar inhibition of monoamine oxidase of mouse brain. The fact that the liver of mammals contains alcohol dehydrogenase suggests that the inhibition of liver monoamine oxidase may occur via the transformation of ethanol to the reactive acetaldehyde, which is responsible for tho observed effects. Further, the level of inhibition observed by Maynard and Schenker is low and requires what amounts to be substrate concentrations of ethanol $(0.022 \quad \mathrm{M}-0.087 \mathrm{M})$. The absence, or a low level, of alcohol dehydrogenase in brain would account for the failure to observe inhibition of monoamine oxidase from this source by ethanol.

The hypothesis that ethanol inhibition of monoamine oxidase is caused by metabolically produced acetaldehyde was tested using rat brain and liver homogenates. Monoamine oxidase activity was followed using the disappearance of sorotonin at $37^{\circ} \mathrm{C}$ by procedures similar to that of Maynard and Schenker ${ }^{1}$, except that liver preparations were incubated for $30 \mathrm{~min}$, and brain preparations for $60 \mathrm{~min}$, and that $1 \cdot 14 \mu$ mole of serotonin was used. Ethanol, when added, was used so that its final concentration was $0.11 \mathrm{M}$. Acetaldehyde was freshly distilled by the procedure outlined by Vogel ${ }^{2}$ and used so that its final concentration was $0.12 \mathrm{M}$. Alcohol dehydrogenase activity was followed by the method of Bonnischen and $\mathrm{Brink}^{3}$.

No alcohol dehydrogenase could be found in brain homogenate; whereas activity in liver was easily detected. In the presence of ethanol, liver monoamine oxidaso was inhibited by 8 per cent when compared with the complete system in the absence of ethanol; with acetaldohyde, the inhibition was increased to 26 por cent. The corresponding values with brain homogenate wero 1 per cent in the presence of othanol, and 36 per cent in the presence of acetaldehyde. 